\title{
Assessing Program Efficiency: A Time and Motion Study of the Mental Health Emergency Care - Rural Access Program in NSW Australia
}

\author{
Emily Saurman ${ }^{1}{ }^{*}$, David Lyle ${ }^{1}$, Sue Kirby ${ }^{1}$ and Russell Roberts ${ }^{2}$
}

1 Broken Hill University Department of Rural Health, University of Sydney, Broken Hill, NSW 2880, Australia; E-Mails: david.lyle@ health.nsw.gov.au (D.L.); sue.kirby@ health.nsw.gov.au (S.K.)

2 University of Sydney, Orange, NSW 2800, Australia; E-Mail: rustleroberts@ hotmail.com

* Author to whom correspondence should be addressed; E-Mail: emily.saurman @ sydney.edu.au; Tel.: +61-(08)-8080-1206; Fax: +61-(08)-8080-1258.

Received: 27 May 2014; in revised form: 15 July 2014 / Accepted: 24 July 2014 /

Published: 31 July 2014

\begin{abstract}
The Mental Health Emergency Care-Rural Access Program (MHEC-RAP) is a telehealth solution providing specialist emergency mental health care to rural and remote communities across western NSW, Australia. This is the first time and motion (T\&M) study to examine program efficiency and capacity for a telepsychiatry program. Clinical services are an integral aspect of the program accounting for $6 \%$ of all activities and $50 \%$ of the time spent conducting program activities, but half of this time is spent completing clinical paperwork. This finding emphasizes the importance of these services to program efficiency and the need to address variability of service provision to impact capacity. Currently, there is no efficiency benchmark for emergency telepsychiatry programs. Findings suggest that MHEC-RAP could increase its activity without affecting program responsiveness. T\&M studies not only determine activity and time expenditure, but have a wider application assessing program efficiency by understanding, defining, and calculating capacity. T\&M studies can inform future program development of MHEC-RAP and similar telehealth programs, both in Australia and overseas.
\end{abstract}

Keywords: mental health; telemedicine; emergency medical services; efficiency; program development; Australia 


\section{Introduction}

The application of telehealth technologies for mental health care is not new and has been used to provide various clinical services and support, supervision and learning, and administrative activities from a distance for decades both in Australia and abroad [1-9]. It is promoted in rural and remote communities to improve access to specialists and the timely and effective provision of quality care [10-13]. Most specialist care in rural Australia, from cardiologists to psychiatrists, is provided by visiting clinicians. Only $16 \%$ of all health specialists consult in rural or remote communities where $30 \%$ of the Australian population resides [14-16].

The provision of specialist mental health care in rural and remote communities is hindered by vast distances, geographic isolation, and ongoing workforce shortages [14,15,17-19]. The management of mental health emergencies in communities without ready access to specialist expertise can result in a delay of referral and/or diagnosis due to underestimating the condition, or the unnecessary transfer of some patients out of their community $[18,20,21]$. The timely intervention with specialist mental health care can reduce patient distress and benefit patient outcomes [18,20,22,23].

The Mental Health Emergency Care-Rural Access Program (MHEC-RAP); a 24/7 rural emergency telepsychiatry program, is contacted through the state freecall mental health telephone access line (1800011511) and aims to improve access to specialist emergency mental health care [24-26]. It has been operating since February 2008 and provides a dedicated team of mental health specialists who offer timely information and support, emergency telephone triage assessments, and video assessments for anyone needing urgent mental health care across the Far West and Western NSW Local Health Districts; a population of approximately 300,000 living across $445,000 \mathrm{kms}^{2}$ or $55 \%$ of the state (Figure 1).

Figure 1. Map of New South Wales (NSW) Local Health Districts (LHD)—Far West LHD and Western NSW LHD identified.

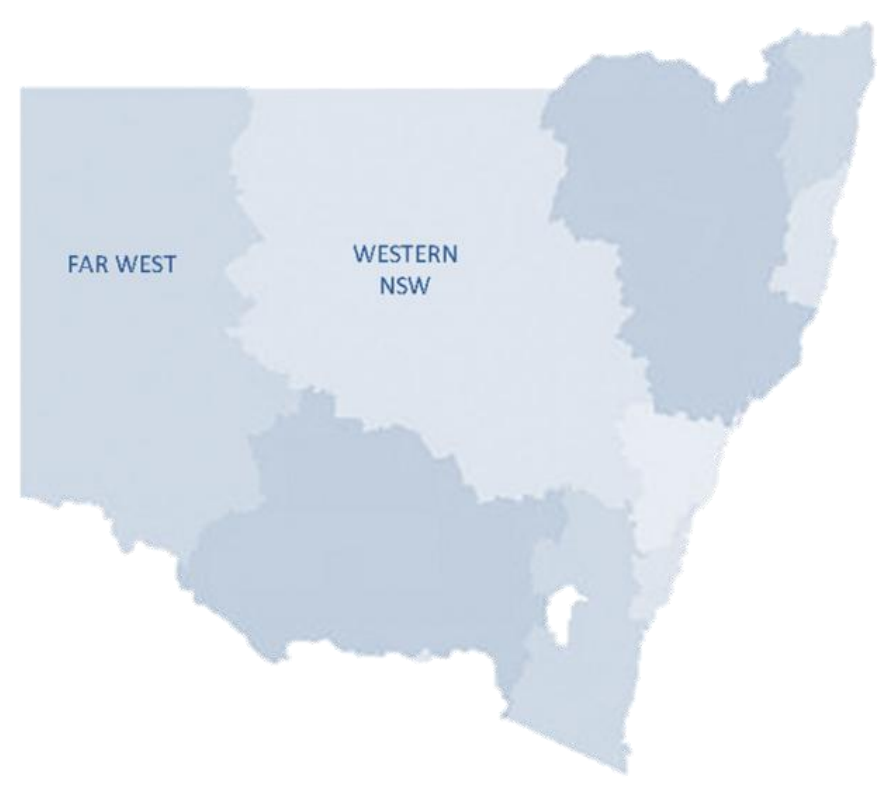

Evaluation findings have already been reported on service activity and program reach [27,28]. The decision to fund the program represents an opportunity cost that needs to be considered both in 
terms of improved access to specialist services and program efficiency. Emergencies are difficult to predict, so an emergency care model needs to balance responsiveness and efficiency to provide value for money. This article presents the findings of a time and motion (T\&M) study that aimed to determine the amount of time required for MHEC-RAP activities and to assess program efficiency based on the model design and current clinical practice.

\section{Method}

A T\&M study was conducted to assess the time taken to complete MHEC-RAP activities and to use these data to inform program development. This was part of a larger study that aimed to describe the structure of MHEC-RAP, how it functions, its processes, and efficiency [29]. T\&M studies are usually associated with work improvement strategies. They are often used for continuous and independent observations of clinical work and have been found to be a more reliable method than work sampling, self-reporting, or questionnaires for documenting process [30-32]. Detailed findings of the observational component of this study, reporting the model design will be published separately.

The "STAMP" (Suggested Time And Motion Procedures) method was used to report our findings. STAMP is a checklist developed for T\&M studies to improve consistency in research and reporting covering areas from the intervention, design, and analysis to the observer and subject [30]. For this study we did not consider cost effectiveness nor the relative efficiency of program delivery compared with other program approaches.

The study took place over 15 consecutive days in April 2013 at the MHEC-RAP facility on the Bloomfield Campus in Orange, NSW. The observations were conducted by ES as part of her PhD Candidature. She was also part of an initial study of MHEC-RAP in 2008 during which time she was co-located with the MHEC-RAP team; this provided useful background knowledge of the program [33]. ES only took a break during an observation period to use the restroom or communicate with her PhD supervisors; food and drink were consumed with the team in the "control room"- the main room from which the team operates.

At the time of the study, MHEC-RAP operated using a 12-h shift schedule with two clinicians rostered on each shift (day/AM and night/PM). A third clinician worked on an overlapping shift each day between 1300-2100. All 17 members of the MHEC-RAP team were invited to participate in the study, including casual staff. As MHEC-RAP is a 24/7 program, observations were scheduled to accommodate non-consenting staff and to ensure observation of day and night shifts across all days of the week. ES observed seven 12-h shifts (3 day/4 night) and four morning sessions (0700-1300) on 11 of $15(73 \%)$ possible days during the study period.

Data were collected in the form of detailed notes (who was acting and what they were doing) and timed activity records (start and finish times of each activity, hour:minute). Activity data were also extracted from the MHEC-RAP call logs and the clinical service dataset for the study period. All notes, activity data, and times were entered on a form created for the purpose, and transcribed into EXCEL spreadsheets for future analysis. Timed activity records were from the initiation of the activity and included all aspects of the activity (including administrative tasks, such as paperwork) through to the completion of the case. For activities that involved more than one rostered clinician, a summary measure of person-time was calculated. 
For these analyses, MHEC-RAP activities were grouped, based on findings from the observational study, into:

- clinical services (the telephone triage and video assessments),

- information services (general information, support, and advice), and

- other program activity (handover, case review, and other case related activity not clinical or information related).

Geometric means and medians were calculated for all analyses because MHEC-RAP activity data were skewed. The Geometric mean normalizes the range of numbers. The median is the middle value of the range and is a robust statistic to report with skewed data.

Three clinical service activities (two telephone triage only and one with video assessment) were managed across shifts so we used mean substitution for the unobserved tasks to calculate the total activity time. Actual time spent on activities during a shift was compared with an estimate based on the geometric mean times to identify outlier observations for more detailed analysis and to inform the use of T\&M findings to estimate program efficiency.

The total available time for MHEC-RAP service provision was calculated as follows: for each 12-h shift two hours were subtracted for meal and work breaks for each clinician, and one hour for the 8-h shift. This resulted in 2820 min of available time for MHEC-RAP service provision each 24-h.

Program efficiency was estimated for the study period (to compare AM and PM shifts) and for a 12 month period using 2011 activity data which was previously collected for the evaluation [27,28]. These data were summarized graphically and used medians because data were skewed. Program efficiency was calculated using the geometric mean times and the activity data; the formulas used, and examples, are in Table 1. All data were analysed using EXCEL and Wessa [34,35].

Table 1. The formulas used to calculate program efficiency of the Mental Health Emergency Care-Rural Access Program.

\begin{tabular}{|c|c|c|}
\hline Variable & Description & Formula and Example Calculation \\
\hline $\mathrm{n}$ & number of days in time period & $\begin{array}{c}\mathrm{n} \\
\text { for example: } 31 \text { days }^{\wedge}\end{array}$ \\
\hline $\mathrm{m}$ & minutes available in time period & $\begin{array}{l}\qquad(\mathrm{n} \times 2820) \\
\text { for example: months of } 31 \text { days } \times 2820=87,420\end{array}$ \\
\hline \multicolumn{3}{|c|}{ CLINICAL SERVICES } \\
\hline cs & number of clinical services for time period & $\begin{array}{c}\text { cs } \\
\text { for example: } 255\end{array}$ \\
\hline va & $\begin{array}{l}\text { number of video assessments } \\
\text { for time period }\end{array}$ & $\begin{array}{c}\text { va } \\
\text { for example: } 71\end{array}$ \\
\hline TVA & total time conducting video assessment & $\begin{array}{l}\qquad(\mathrm{va} \times 126.35) \\
\text { for example: } 71 \times 126.35=8970.85\end{array}$ \\
\hline $\operatorname{tr}$ & $\begin{array}{l}\text { number of telephone triages } \\
\text { for time period }\end{array}$ & $\begin{array}{c}\text { (cs-va) } \\
\text { for example: } 184 \\
\end{array}$ \\
\hline TTR & total time conducing telephone triage & $\begin{array}{l}\qquad(\operatorname{tr} \times 64.81) \\
\text { for example: } 184 \times 64.81=11,925.04\end{array}$ \\
\hline TCS & total time conducting clinical services & $\begin{array}{c}(\text { TVA }+ \text { TTR }) \\
\text { for example: } 8970.85+11,925.04=20,895.89\end{array}$ \\
\hline
\end{tabular}


Table 1. Cont.

\begin{tabular}{|c|c|c|}
\hline Variable & Description & Formula and Example Calculation \\
\hline $\mathrm{W}$ & $\begin{array}{l}\text { proportion of total available time } \\
\text { conducting clinical services for } \\
\text { time period }\end{array}$ & $\begin{array}{l}\qquad(\mathrm{TCS} / \mathrm{m}) \text { or }((\mathrm{TVR}=\mathrm{TTR}) / \mathrm{m}) \\
\text { for example: month of } 31 \text { days }=23.90\end{array}$ \\
\hline \multicolumn{3}{|c|}{ INFORMATION SERVICES } \\
\hline in & $\begin{array}{l}\text { number of incoming case related calls } \\
\text { (not related to cs) for time period }\end{array}$ & $\begin{array}{l}\text { in } \\
\text { for example: } 782\end{array}$ \\
\hline TIN & total time conducting incoming calls & $\begin{array}{l}\qquad(\text { in } \times 2.51) \\
\text { for example: } 782 \times 2.51=1962.82\end{array}$ \\
\hline ot & $\begin{array}{l}\text { number of outgoing case related calls } \\
\text { (not related to cs) for time period }\end{array}$ & $\begin{array}{c}\text { ot } \\
\text { for example: } 193\end{array}$ \\
\hline TOT & total time conducting outgoing calls & $\begin{array}{l}\qquad(\text { ot } \times 1.68) \\
\text { for example: } 193 \times 1.68=324.24\end{array}$ \\
\hline TIS & total time conducting information services & $\begin{array}{c}(\text { TIN }+ \text { TOT }) \\
\text { for example: } 1962.82+324.24=2287.06\end{array}$ \\
\hline $\mathrm{x}$ & $\begin{array}{l}\text { proportion of total available time } \\
\text { conducting information services for } \\
\text { time period }\end{array}$ & $\begin{array}{l}(\mathrm{TIS} / \mathrm{m}) \text { or }((\mathrm{TIN}+\mathrm{TOT}) / \mathrm{m}) \\
\text { for example: } \text { month of } 31 \text { days }=2.62\end{array}$ \\
\hline \multicolumn{3}{|c|}{ OTHER PROGRAM ACTIVITIES } \\
\hline oa & $\begin{array}{l}\text { time conducting other program activities } \\
\text { (handover, casereview, otheractivities) }\end{array}$ & $\begin{array}{c}\text { handoverAM = minsx2staff; handoverPM = } \\
\text { minsx2staff; casereviewAM = minsx2staff; } \\
\text { otheractivitiesAM = mins; otheractivitesPM = mins }\end{array}$ \\
\hline oawd & weekday variation & $\begin{array}{c}\text { handover(AM + PM })+ \text { casereview AM + } \\
\text { otheractivities }(\mathrm{AM}+\mathrm{PM}) \text { for example: } \\
25.42+13.00+81.04+14.50+3.33=137.29\end{array}$ \\
\hline oawe & weekend variation & $\begin{array}{l}\text { handover(AM + PM })+ \text { otheractivities }(\mathrm{AM}+\mathrm{PM}) \\
\text { for example: } 25.42+13.00+14.50+3.33=56.25\end{array}$ \\
\hline TOA & total time conducting other activities & $\begin{array}{c}(\text { oawd } x n)+(\text { oawe } x n) \text { for example: month of } \\
31 \text { days }=(137.29 \times 21)+(56.25 \times 10)=3445.59\end{array}$ \\
\hline $\mathrm{y}$ & $\begin{array}{l}\text { proportion of total available time } \\
\text { conducting other program activity for } \\
\text { time period }\end{array}$ & $\begin{array}{l}(\mathrm{TOA} / \mathrm{m}) \text { or }((\text { oawd } \mathrm{xn})+(\text { oawe } \mathrm{xn}) / \mathrm{m}) \\
\text { for example: } \text { month of } 31 \text { days }=3.94\end{array}$ \\
\hline \multicolumn{3}{|c|}{ TOTAL TIME } \\
\hline TT & total time spent in activity & $\begin{array}{c}\text { (TCS + TIS + TOA) for example: } \\
20,895.89+2287.06+3445.59=26,628.54\end{array}$ \\
\hline Z & $\begin{array}{l}\text { proportion of total available time } \\
\text { spent in activity for time period }\end{array}$ & $\begin{array}{l}(\mathrm{TT} / \mathrm{m}) \text { or }(\mathrm{w}+\mathrm{x}+\mathrm{y}) \\
\text { for example: } \text { month of } 31 \text { days }=30.46\end{array}$ \\
\hline
\end{tabular}

$\wedge$ Numbers in the examples are those for January 2011.

\section{Results}

\subsection{Time and Motion}

There were 299 activities observed during the study period-18 clinical services, 239 information services, and 42 other program activities. Information services accounted for $80 \%$ of overall activity in 
terms of numbers, but only $21 \%$ in terms of time with each telephone call lasting 2-3 min on average. The clinical services accounted for $6 \%$ of all activities and $50 \%$ of the time for those activities.

It took $65 \mathrm{~min}$ on average to complete a telephone triage, increasing twofold to $126 \mathrm{~min}$ when a video assessment was organized as well. Time required for the clinical care component ranged from a minimum of $8 \mathrm{~min}$ for telephone triage only to a maximum of $96 \mathrm{~min}$ with a video assessment, averaging 17 and $47 \mathrm{~min}$ respectively. Arranging care required 4 to $5 \mathrm{~min}$ on average, however in one instance this took $51 \mathrm{~min}$. Completing the associated clinical paperwork accounted for more than half the time taken to deliver a clinical service- $63 \%$ for telephone triage only and $52 \%$ with a video assessment (Table 2).

Table 2. Time expenditure for the Mental Health Emergency Care-Rural Access Program by activity, 15 consecutive days in April 2013.

\begin{tabular}{|c|c|c|c|c|c|}
\hline \multirow[b]{2}{*}{ Activity } & \multirow[b]{2}{*}{$\begin{array}{l}\text { Number } \\
\text { Observed }\end{array}$} & \multicolumn{4}{|c|}{ Geometric Mean Time } \\
\hline & & $\begin{array}{c}\text { Total Time } \\
\text { Mins (Range) }\end{array}$ & $\begin{array}{l}\text { Clinical Care } \\
\text { Mins (Range) }\end{array}$ & $\begin{array}{c}\text { Arranging Care } * \\
\text { Mins (Range) }\end{array}$ & $\begin{array}{l}\text { Paperwork ** } \\
\text { Mins (Range) }\end{array}$ \\
\hline \multicolumn{6}{|c|}{ CLINICAL SERVICES } \\
\hline Telephone Triage only & 8 & $64.81(26-165)$ & $17.35(8-75)$ & $4.02(2-9)$ & $39.13(13-152)$ \\
\hline with Video Assessment & 10 & $126.35(49-309)$ & $47.10(20-96)$ & $5.01(2-51)$ & $58.79(12-174)$ \\
\hline \multicolumn{6}{|c|}{ INFORMATION SERVICES } \\
\hline Incoming Call & 132 & $2.51(1-36)$ & $\mathrm{NA}^{\wedge \wedge}$ & NA & NA \\
\hline Outgoing Call & 107 & $1.68(1-15)$ & NA & NA & NA \\
\hline \multicolumn{6}{|c|}{ OTHER PROGRAM ACTIVITY } \\
\hline Handover(AM) $* * *$ & 7 & $25.42(12-54)$ & NA & NA & NA \\
\hline Handover(PM) $* * *$ & 4 & $13.00(4-24)$ & NA & NA & NA \\
\hline Case Review(AM) $* * *$ & 6 & $81.04(40-168)$ & NA & NA & NA \\
\hline Other Activity $(\mathrm{AM})^{\wedge}$ & 16 & $14.50(1-45)$ & NA & NA & NA \\
\hline Other Activity $(\mathrm{PM})^{\wedge}$ & 9 & $3.33(1-8)$ & NA & NA & NA \\
\hline
\end{tabular}

* Arranging Care is time spent contacting referral and transport services; ** Paperwork is the time spent completing the required documentation (Triage, Assessment, Discharge Forms); *** Reporting person minutes based on 2 persons participating per shift; ^ Other activity includes discussions, following-up on a case, completing data logs, and other case related activities that are not clinical or information service related; $\wedge$ NA $=$ Not Applicable.

Case reviews were conducted each weekday (AM shift) and involved the supervising psychiatrist, the two rostered MHEC-RAP clinicians, and the Nurse Unit Manager. This activity required 81 person-min on average. Clinical handover occurred twice a day between shifts, and took 25 person-min on average for the AM shift and 13 person-min for the PM shift.

We compared the time spent on activities during the observation period with an estimate based on the mean times (Figure 2). The predictive model underestimated the actual times, (mean difference-54.55 min $\mathrm{t}_{10 \mathrm{df}}=2.35, p<0.05$ ). We reviewed the four shifts whose actual times exceeded the predicted values by more than 50\%. For three, between $57 \%$ and $100 \%$ of the difference was accounted for by the additional time spent completing paperwork in excess of the average, and for the fourth, which had only one clinical service, all of the difference was attributed to a lengthy case review and other program activities. 
Figure 2. Scatterplot comparing the observed and predicted times (in minutes) conducting Mental Health Emergency Care-Rural Access Program Activities during 12-h shifts (blue) and 6-h shifts (green), April 2013.

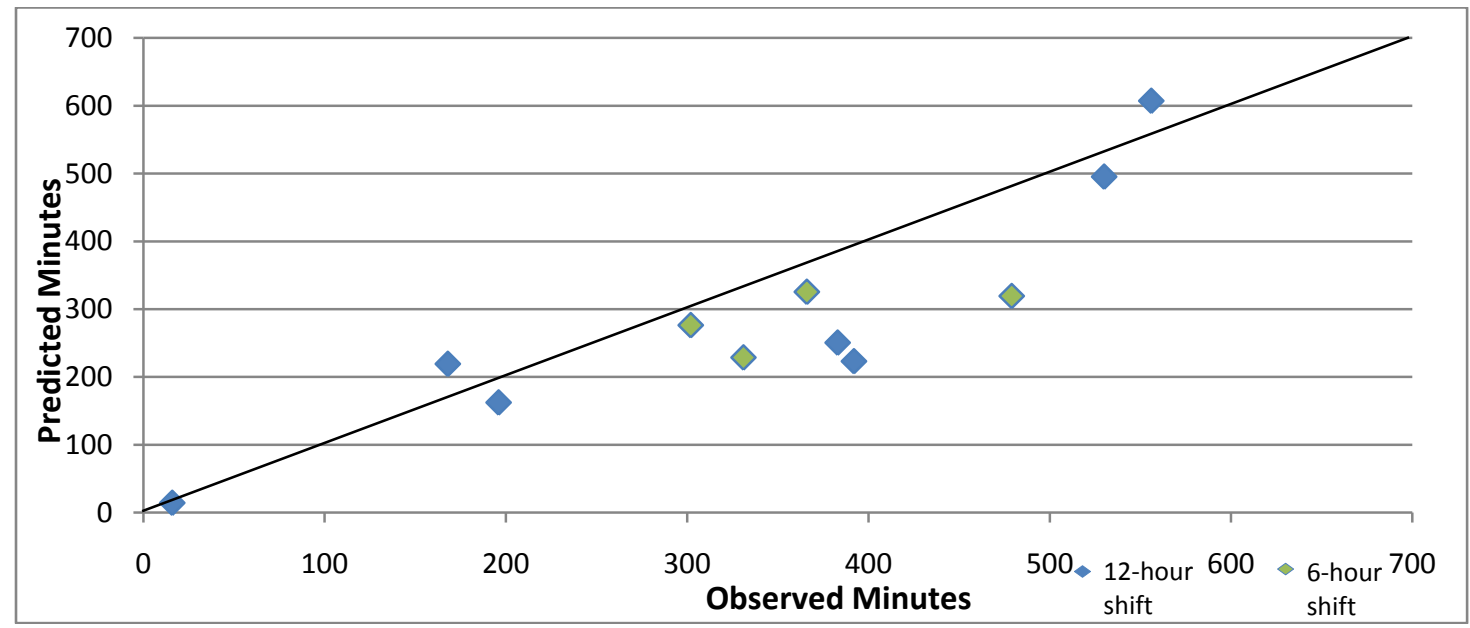

\subsection{Program Efficiency}

The estimated time spent providing MHEC-RAP activities varied between the AM and PM shifts during the study period (Figure 3). This represented a median of $28 \%$ of the available time for the AM shift (range: $4 \%-65 \%$ ) and $20 \%$ of the PM shift (range: $2 \%-56 \%$ ). However when case review was excluded from the weekday AM shifts, the median was 22\% (range: 4\%-59\%) indicating similar amounts of time was spent on clinical service activity for both the AM and PM shifts.

Figure 3. The proportion of available time in active service provision-Mental Health Emergency Care-Rural Access Program, 15 consecutive days in April 2013.

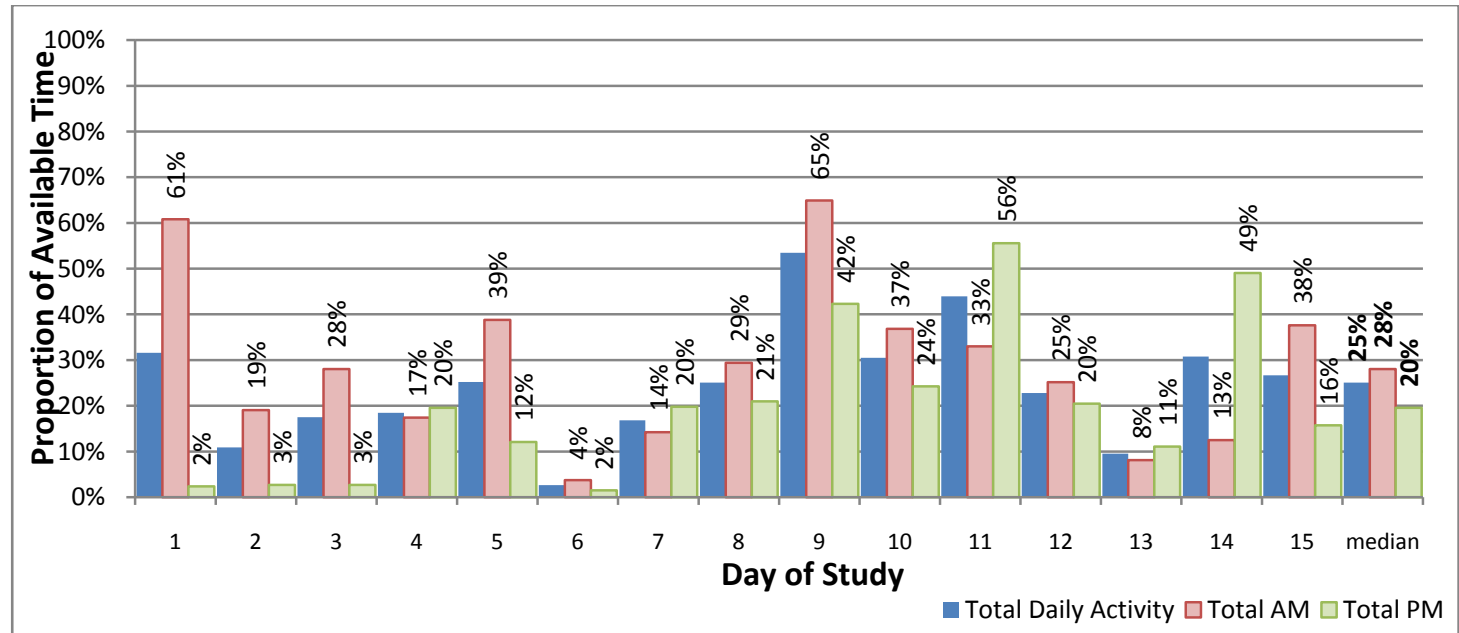

In 2011, we estimated that a median of $26 \%$ (range $7 \%-61 \%$ ) of the available time was spent providing MHEC-RAP activities on a daily basis. The estimated time spent on MHEC-RAP activities exceeded $50 \%$ of the available time for only 5 days in 2011 . For 175 days that year, less than a quarter of the available time each day was spent providing program activities (Figure 4). 
Figure 4. The proportion of available time spent providing Mental Health Emergency Care-Rural Access Program activities on a daily basis in 2011.

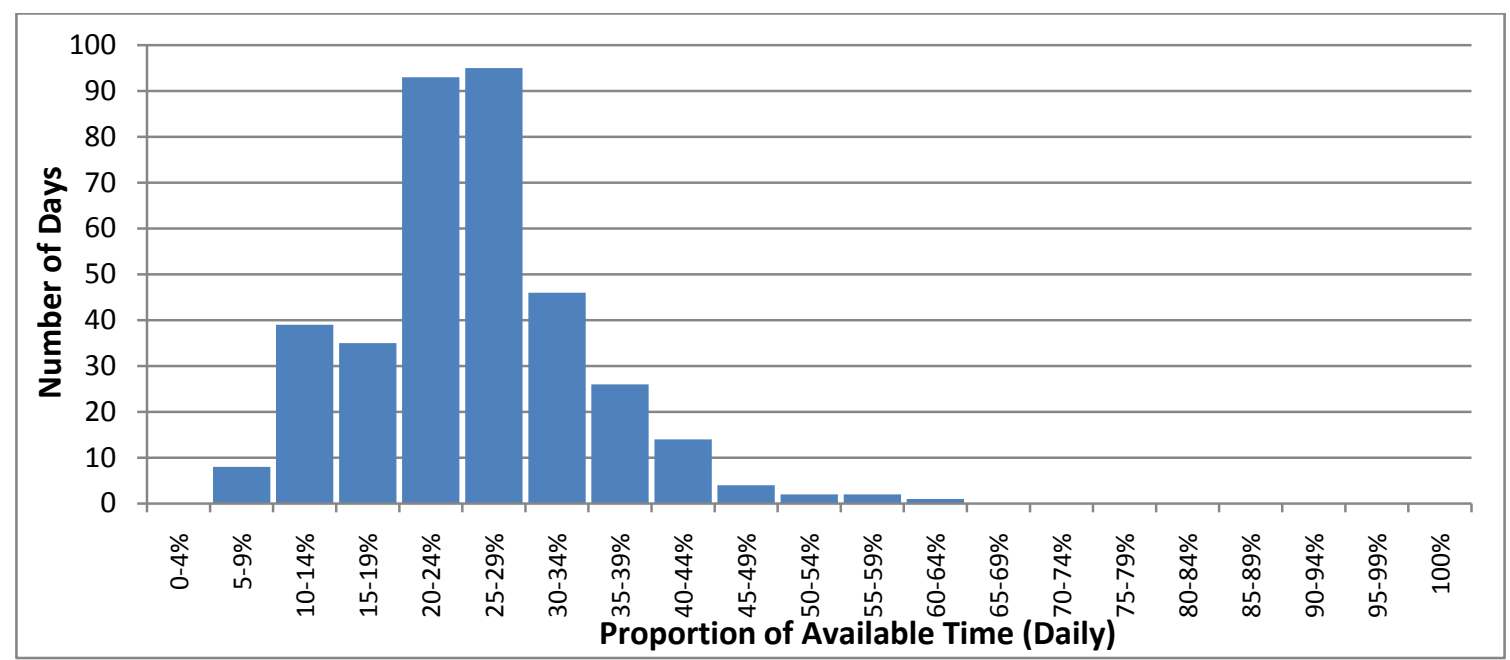

\section{Discussion}

This T\&M study provided valuable information, not otherwise available, about the amount of time required for MHEC-RAP activities and program efficiency. It emphasized the importance of telephone triage and video assessment activity in relation to program efficiency (mean time required of $65 \mathrm{~min}$ and 126 min respectively for each activity). Even at low levels of activity they accounted for the majority of time spent on service delivery and thus represent the most important determinant of program efficiency. One area that would benefit from more efficient service delivery is the completion of paperwork, which accounted for at least $50 \%$ of the time required for a clinical service. This activity showed significant variability and has the potential to impact program performance if it is not effectively managed.

The T\&M study findings have wider application. During 2011, the estimated time required for MHEC-RAP activities accounted for about one-quarter of the available time and only exceeded half of the available time on five days that year. This indicated that the program had capacity to support a higher level of clinical service activity. Currently, there is no efficiency benchmark for emergency telehealth mental health care programs. T\&M studies could be used to derive benchmarks for efficient service delivery and inform the development of similar telehealth programs, both in Australia and overseas. Like other emergency services, MHEC-RAP must manage efficiency against capacity and based on our data, an initial increase in activity to achieve a median of $40 \%$ of the available time in active service provision should be possible without adversely affecting program responsiveness. Increased activity would result in greater program efficiency and further address the aim to improve access to the service. For MHEC-RAP, this could be achieved by promoting greater use of the program within the existing service footprint or extending the program reach to additional communities in adjacent regions.

Future research could provide more detailed breakdown of the different elements of MHEC-RAP activities including the time taken to coordinate the admission and transportation of patients requiring specialist care in a Mental Health Inpatient Unit, for supervision and support of generalist staff to manage patients in the local ED, and support of community mental health staff in smaller centres. 
Additional investigations could review MHEC-RAP against the standards for NSW Health Mental Health Telephone Triage Services such as the time to answer a call and compare the time taken to complete telephone triage and video assessment by referral source to provide a greater understanding of program performance [36].

The design specifications for similar telehealth programs, including geographical reach and minimum staffing levels, influence demand for the service and their capacity to manage workload. Nonetheless, getting program efficiency right is primarily a function of maximizing the number of emergencies referred to the service, on average, over an extended period, with adjustments for the variability in numbers on a daily basis to maintain service responsiveness. Further work is required to generate metrics that would enable benchmarks to be established and calculations to be made that set realistic program efficiency targets and assist service planning.

\section{Limitations and Strengths}

The study is based on a small number of clinical services collected during a period of low program activity which reduced the precision of study estimates. The lack of time pressure on some shifts may have influenced the amount of time taken to complete certain activities such as the completion of paperwork, resulting in prolonged times. Program efficiency measures were derived from routinely collected data accessed through MHEC-RAP service records for 2011. Data were limited to a daily count of clinical activities and a summary of in-coming and outgoing calls on a monthly basis restricting our analysis to daily measures of program efficiency and potentially reducing the variance of those daily estimates.

The use of well accepted and robust T\&M methods, based on independent observation of activity and administered by one observer, are study strengths that support the validity of the findings.

\section{Conclusions}

MHEC-RAP is not the first telehealth service to be developed in Australia or overseas, but it is the first model to combine 24-h availability and access to regionally-based emergency specialist care using telehealth technology. The T\&M study provided valuable information, not otherwise available, about the amount of time required for MHEC-RAP processes and program efficiency. The study emphasized the importance of telephone triage and video assessment activity in relation to program efficiency and that the program had capacity to support a higher level of clinical service activity. The T\&M study findings have wider application and could be used to derive benchmarks for efficient service delivery and inform the development of similar telehealth programs, both in Australia and overseas.

\section{Acknowledgments}

The cooperation and assistance of the Mental Health Emergency Care-Rural Access Program team was much appreciated.

Ethics approval was received from the Greater Western Human Research Ethics Committee: Project Number HREC/13/GWAHS/9.

This article will be published as part of the PhD Thesis of Emily Saurman. 
This research is a project of the Centre of Research Excellence in Rural and Remote Primary Health Care, Australian Primary Health Care Research Institute, which is supported by a grant from the Commonwealth of Australia, the Department of Health and Ageing. The information and opinions contained within do not necessarily reflect the views or policy of the Australian Primary Health Care Research Institute, the Commonwealth of Australia, or the Department of Health and Ageing.

The Broken Hill University Department of Rural Health is funded by the Australian Government Department of Health and Ageing.

\section{Author Contributions}

Emily Saurman: Acquisition of data, analysis and interpretation of data, drafting of the manuscript, critical revision of the manuscript, and final approval; David Lyle: Interpretation of data, drafting of the manuscript, and critical revision of the manuscript; and Sue Kirby: Critical revision of the manuscript; Russell Roberts: Critical revision of the manuscript.

\section{Conflicts of Interest}

The authors declare no conflict of interest

\section{References}

1. Lessing, K.; Blignault, I. Mental health telemedicine programmes in Australia. J. Telemed. Telecare 2001, 7, 317-324.

2. Hawker, F.; Kavanagh, S.; Yellowlees, P.; Kalucy, R.S. Telepsychiatry in South Australia. J. Telemed. Telecare 1998, 4, 187-194.

3. Hilty, D.M.; Ferrer, D.C.; Parish, M.B.; Johnston, B.; Callahan, E.J.; Yellowlees, P.M. The effectiveness of telemental health: A 2013 review. Telemed. J. E Health 2013, 19, 444-454.

4. Trondsen, M.; Bolle, S.; Stensland, G.; Tjora, A. VIDEOCARE: Decentralised psychiatric emergency care through videoconferencing. BMC Health Serv. Res. 2012, 12, doi:10.1186/1472-6963-12-470.

5. Yellowlees, P.; Kavanagh, S. The use of telemedicine in mental health service provision. Australas. Psychiatry 1994, 2, 268-270.

6. Vaitheswaran, S.; Crockett, P.; Wilson, S.; Millar, H. Telemental health: Videoconferencing in mental health services. Adv. Psychiatr. Treat. 2012, 18, 392-398.

7. Yellowlees, P.M.; Kennedy, C. Telemedicine: Here to stay. Med. J. Aust. 1997, 166, 262-265.

8. Yellowlees, P.; Burke, M.M.; Marks, S.L.; Hilty, D.M.; Shore, J.H. Emergency telepsychiatry. J. Telemed. Telecare 2008, 14, 277-281.

9. Buist, A. Telepsychiatry in Australia. In Telepsychiatry and E-Mental Health; Richard Wootton, P.Y., McLaren, P., Eds.; Royal Society of Medicine Press Ltd: London, UK, 2003; pp. 113-123.

10. Ellis, I. Is telehealth the right tool for remote communities? Improving health status in rural Australia-Editorial. Contemp. Nurse A J. Aust. Nurs. Prof. 2004, 16, 163-168.

11. Moffatt, J.J.; Eley, D.S. The reported benefits of telehealth for rural Australians. Aust. Health Rev. 2010, 34, 276-281. 
12. Norman, S. The use of telemedicine in psychiatry. J. Psychiatr. Ment. Health Nurs. 2006, 13, 771-777.

13. Sevean, P.; Dampier, S.; Spadoni, M.; Strickland, S.; Pilatzke, S. Patients and families experiences with video telehealth in rural/remote communities in Northern Canada. J. Clin. Nurs. 2009, 18, 2573-2579.

14. Rajkumar, S.; Hoolahan, B. Remoteness and issues in mental health care: Experiences from rural Australia. Epideniologia Psichiatr. Soc. 2004, 13, 78-82.

15. Dunbar, J.; Hickie, I.; Wakerman, J.; Reddy, P. New money for mental health: Will it make things better for rural and remote Australia? Med. J. Aust. 2007, 186, 587-589.

16. Australian Institute of Health and Welfare. Rural, Regional and Remote Health: Indicators of Health Status and Determinants of Health; Cat. No. PHE 97; Australian Institute of Health and Welfare: Canberra, Australia, 2008.

17. Standing Council on Health. National Strategic Framework for Rural and Remote Health; Standing Council on Health: Canberra, Australia, 2012.

18. National Advisory Council of Mental Health. A Mentally Health Future for All Australians, a Discussion Paper; NACMH: Canberra, Australia, 2009.

19. Judd, F.K.; Humphreys, J.S. Mental health issues for rural and remote Australia. Aust. J. Rural Health 2001, 9, 254-258.

20. Westwood, B.; Westwood, G. Multi-presenter mental health patients in emergency departmentsA review of models of care. Aust. Health Rev. 2001, 24, 202-213.

21. Stuhlmiller, C.M.; Tolchard, B.; Thomas, L.J.; Crespigny, C.F.D.; Kalucy, R.S.; King, D. Increasing confidence of emergency department staff in responding to mental health issues: An educational initiative. Aust. Emerg. Nurs. J. 2004, 7, 9-17.

22. O’Reilly, R.; Bishop, J.; Maddox, K.; Hutchinson, L.; Fisman, M.; Takhar, J. Is telepsychiatry equivalent to face-to-face psychiatry? Results from a randomised controlled equivalence trial. Psychiatr. Serv. 2007, 58, 836-843.

23. Fuller, J.; Edwards, J.; Procter, N.; Moss, J. Mental health in rural and remote Australia. In the New Rural Health; Wilkinson, D., Blue, I., Eds; Oxford University Press: Melbourne, Australia, 2002.

24. Greater Western Area Health Service. Mental Health Emergency Care-Rural Access Project, Draft Version 2.; Greater Western Area Health Service: New South Wales, Australia, 2007.

25. NSW Health. The Rural Mental Health Emergency and Critical Care Access Plan; Mental Health and Drug and Alcohol Organisation Working Group: New South Wales, Australia, 2007; pp 1-20.

26. NSW Health, NSW TeleHealth: Information for Health Professionals. 2002. Available online: http://www.chw.edu.au/prof/telehealth/nsw_health_professional_telehealth_brochure.pdf (acessed on 27 May 2014).

27. Saurman, E.; Lyle, D.; Perkins, D.; Roberts, R. The successful provision of emergency mental health care to rural and remote NSW-An evaluation of the Mental Health Emergency Care-Rural Access Program. Aust. Health Rev. 2014, 38, 58-64.

28. Saurman, E.; Lyle, D.; Kirby, S.; Roberts, R. Accessing specialist emergency mental health care in rural and remote emergency departments-Use of the Mental Health Emergency Care-Rural Access Program. J. Telemed. Telecare 2014, 38, 58-64. 
29. Angrosino, M. Doing Ethnographic and Observational Research; Sage Publications Inc.: Thousand Oaks, CA, USA, 2007.

30. Zheng, K.; Guo, M.H.; Hanauer, D.A. Using the time and motion method to study clinical work processes and workflow: Methodological inconsistencies and a call for standardized research. J. Am. Med. Inform. Assoc. 2011, 18, 704-710.

31. Webster, J.; Davies, H.; Stankiewicz, M.; Fleming, L.C. Estimating the time involved in managing the "unoccupied bed": A time and motion study. Nurs. Econ. 2011, 29, 317-322.

32. Burke, T.A.; McKee, J.R.; Wilson, H.C.; Donahue, R.M.J.; Batenhorst, A.S.; Pathak, D.S. A comparison of time-and-motion and self-reporting methods of work measurement. J. Nurs. Adm. 2000, 30, 118-125.

33. Saurman, E.; Perkins, D.; Roberts, R.; Roberts, A.; Patfield, M.; Lyle, D. Responding to mental health emergencies: Implementation of an innovative telehealth service in rural and remote NSW, Australia. J. Emerg. Nurs. 2011, 37, 453-459.

34. Microsoft Office Excel, 2010. Available online: http://office.microsoft.com/en-us/excel/ (acessed on 27 May 2014).

35. Wessa, P. Free Statistics Software v.1.1.23-r7, 2013. Available online: http://www.wessa.net/ (accessed on 27 May 2014).

36. NSW Health. Mental Health Triage Policy, PD2012_053. 2012 Available online: http://www0.health.nsw.gov.au/policies/pd/2012/pdf/PD2012_053.pdf (acceseed on 27 May 2014).

(C) 2014 by the authors; licensee MDPI, Basel, Switzerland. This article is an open access article distributed under the terms and conditions of the Creative Commons Attribution license (http://creativecommons.org/licenses/by/3.0/). 